\title{
Grain storage: the management of ecological change - abstract
}

\author{
J. Lacey \\ A.F.R.C. Institute of Arable Crops Research, Rothamsted Experimental Station, \\ Harpenden, Hertfordshire AL5 2JQ, U.K.
}

\section{The grain ecosystem}

Grain stored in bulk forms a man-made ecosystem with a limited, non-regenerating energy supply. However, frequent interference results in an immature, unstable ecosystem with a relatively simple structure and composed of species with limited specialisation, and high growth and reproductive rates. Microbial colonisation commences soon after ear emergence, by what have been termed "field" fungi. These usually have a minimum water potential for germination of $-22.4 \mathrm{MPa}(>0.85 \mathrm{aw})$, have to contend with large diurnal changes in environmental conditions and seldom develop further in store. Sometimes, especially in humid tropical climates, species more typical of stored grain ("storage fungi") also develop before harvest, and even produce mycotoxins. This differentiation between fungi characteristic of field or store is historical and their classification on ecological requirements would be preferable.

When grain is harvested, it becomes contaminated with storage fungi and the ecosystem is drastically disturbed. Subsequent hot air drying may increase the risk of moulding in store. Conditions in stored grain become more stable than in the field, with smaller diurnal temperature changes and with water availability controlled by grain water content. Microclimatic conditions, especially temperature, water potential and gaseous regime, determine the microorganisms that can grow, the rate of their growth and the extent of spontaneous heating. Aspergillus and Penicillium spp. are the most characteristic storage fungi but, in heated grain at high water potential, thermotolerant fungi and actinomycetes occur. The predominant species can be good indicators of the previous storage conditions. Field fungi persist at low water potential but a small increase can greatly increase the activity of storage fungi so that field fungi decline rapidly. The most xerophilic storage fungi grow to about $-59.3 \mathrm{MPa}(0.65 \mathrm{aw})$.

Storage fungi are usually considered obligate aerobes but often the concentration of $\mathrm{O}_{2}$ has to be decreased to $<0.14 \%$ to halve linear growth rates. Their growth is sometimes stimulated by low $\mathrm{CO}_{2}$ concentrations and tolerance of high $\mathrm{CO}_{2}$ concentrations may be diminished by decreasing $\mathrm{O}_{2}$ concentrations. Many interactions between abiotic and biotic variables occur in stored grain. Water potential, temperature and period of storage all affect moulding and insect infestation, while competitive interactions are found between field storage fungi, within each group and between fungi and arthropods. Insects and mites grow and reproduce on some fungi and are inhibited or infected by others. Their faeces provide substrates for microbial colonisation and they assist fungal invasion of grain through feeding damage, increased water availability and increased temperature. 


\section{Management of ecological change}

Drying grain decreases the number of species that can grow and retards spore germination, growth and sporulation. Decreasing water potential to $-45.2 \mathrm{MPa}$ $(0.72 \mathrm{aw})$ allows storage for up to three months while decreasing to $-59.3 \mathrm{MPa}$ $(0.65 \mathrm{aw})$ allows storage for one to two years. Higher water potentials used in commerce are not safe for storage. Moisture migration from warm to cooler areas increases grain water content, leading to spontaneous heating and the formation of "hot spots". Fungal-induced hot spots can develop rapidly, even when ambient temperatures are below freezing, following a period of fungal development. Temperature and water potential can also regulate competitive ability and the production of enzymes and secondary metabolites, including mycotoxins.

Low rate ventilation with ambient air may be used in cool climates to create uniform conditions in stored grain by removing respiratory heat, $\mathrm{CO}_{2}$ and water vapour, so preventing moisture migration. By cooling the grain below $10^{\circ} \mathrm{C}$, mould development is slowed, allowing up to eight months storage with little moulding, although musty odours may still occur. Rapid chilling by ventilating with refrigerated air can also be used to limit fungal deterioration, although the degree of chilling required changes markedly with water potential. Some field and storage fungi can grow at temperatures down to $-6^{\circ} \mathrm{C}$ and may even produce mycotoxins in grain at these temperatures.

Sealed and unsealed storage of damp grain and controlled-atmosphere storage of drier grain utilise the sensitivity of fungi to high $\mathrm{CO}_{2}$ and low $\mathrm{O}_{2}$ concentrations. $\mathrm{O}_{2}$ is replaced by $\mathrm{CO}_{2}$ through respiration in damp grain to give $60-85 \% \mathrm{CO}_{2}$ and $1 \%$ $\mathrm{O}_{2}$ within seven days. Increasingly aerobic conditions, after loss of $\mathrm{CO}_{2}$ through gaseous exchange with the external atmosphere caused by diurnal pressure fluctuations or diffusion with too slow removal of grain, can eventually lead to moulding. Artificially controlled atmospheres with added $\mathrm{CO}_{2}$ or $\mathrm{N}_{2}$ produce rapid anaerobic conditions in fairly dry grain but the regimes proposed are often designed for insect control and are insufficient to prevent moulding.

Volatile fatty acids, especially propionic acid, have been used to preserve grain for animal feed but are fungistatic rather than fungicidal. Fungi differ in their susceptibility and, consequently, application must be uniform and adequate for the water content. Undertreatment can lead to the growth of tolerant species that metabolise the acid, less tolerant species then develop and finally a succession characteristic of untreated grain occurs and the risk of mycotoxin production increases.

Insects and mites are important in their own right as agents of deterioration of cereal grains, but their control also contributes to the control of microorganisms. Above $17^{\circ} \mathrm{C}$, insect infestation is independent of water potential. Mite infestations can occur between 3 and $30^{\circ} \mathrm{C}$ if water potential is above about $-90.0 \mathrm{MPa}(0.52 \mathrm{aw})$ leading to spontaneous heating in grain that is too dry for fungal heating.

Broken grains and foreign material often separate into discrete zones when grain stores are filled and interfere with ventilation. They may differ in water potential from the grain, be more susceptible to moulding and, unless removed, provide a focus for fungal and insect infestation. Irradiation can be used to sterilise grain before storage but doses up to $12 \mathrm{KGy}$ are necessary. 


\section{Conclusion: prospects for integrated control}

To minimise deterioration, all storage systems seek to maintain grain in an unstable equilibrium by modifying the environment, e.g. by drying or chilling the grain, by modifying the intergranular gaseous environment or with chemicals. Most systems rely on the control of only one factor, neglecting the possibility of interactions or synergism. Control of some factors can sometimes be expensive or impractical with existing stores and require heavy use of energy for drying or chilling, large quantities of expensive fungistatic chemicals or large doses of radiation and may also require special buildings, such as sealed stores that can maintain large concentrations of $\mathrm{CO}_{2}$ or $\mathrm{N}_{2}$. The use of integrated methods of control that rely on the modification of several parameters to obtain savings in costs without diminishing the efficiency of control require investigation.

The full text of this paper will be published in the Proceedings of the Seventh International Biodeterioration Symposium which was held in Cambridge from 7-1 I September 1987 as Biodeterioration 7, eds. Houghton, D. R., Smith, R. N. \& Eggins, H. O. W. Barking: Elsevier Applied Science Publishers. 